NBER WORKING PAPER SERIES

\title{
WOMEN HELPING WOMEN? ROLE-MODEL AND MENTORING EFFECTS ON FEMALE \\ PH.D. STUDENTS IN ECONOMICS
}

\author{
David Neumark \\ Rosella Gardecki
}

Working Paper 5733

\section{NATIONAL BUREAU OF ECONOMIC RESEARCH 1050 Massachusetts Avenue \\ Cambridge, MA 02138 \\ August 1996}

We thank Jodi Messer and Ramona Taylor for assistance with the research, and Kathleen Beegle, Robert LaLonde, and Jennifer Tracey for helpful comments. This paper is part of NBER's research program in Labor Studies. Any opinions expressed are those of the authors and not those of the National Bureau of Economic Research.

(C) 1996 by David Neumark and Rosella Gardecki. All rights reserved. Short sections of text, not to exceed two paragraphs, may be quoted without explicit permission provided that full credit, including (C) notice, is given to the source. 


\title{
WOMEN HELPING WOMEN? ROLE-MODEL AND MENTORING EFFECTS ON FEMALE \\ PH.D. STUDENTS IN ECONOMICS
}

\begin{abstract}
One potential method to increase the success of female graduate students in economics may be to encourage mentoring relationships between these students and female faculty members. Increased hiring of female faculty is viewed as one way to promote such mentoring relationships, perhaps because of role-model effects. A more direct method of promoting such relationships may be for female graduate students to have female faculty serve as dissertation chairs. The evidence in this paper addresses the question of whether either of these strategies results in more successful outcomes for female graduate students. The evidence is based on survey information on female graduate students and faculties of Ph.D.-producing economics departments, covering the mid-1970s to the early 1990 s.

With respect to characteristics of the institutions at which students are first placed when leaving graduate school, the empirical evidence provides no support for the hypothesis that outcomes for female graduate students are improved by adding female faculty members, or by having a female dissertation chair. However, with respect to time to complete graduate school, and the completion rate, there is some limited evidence of beneficial effects of female faculty members.
\end{abstract}

David Neumark

Department of Economics

Michigan State University

East Lansing, MI 48824

and NBER

dneumark@msu.edu
Rosella Gardecki

Department of Economics

Michigan State University

East Lansing, MI 48824 


\section{$\underline{\text { I. Introduction }}$}

Women in the economics profession are underrepresented at all academic levels, leave graduate programs at higher rates, and achieve tenure at lower rates than their male counterparts (Kahn, 1995). This is despite the fact that men and women apparently have equivalent probabilities of being admitted to graduate school and of graduating from the top-tier graduate programs (Attiyeh and Attiyeh, 1994). There are a variety of possible explanations for the underrepresentation of women in economics, ranging from discrimination to preferences to optimal human capital investment. However, a number of sources have cited the lack of same-sex mentoring in the economics profession as contributing to the relative scarcity of female economists (Horn, 1994), and steps are being taken to encourage mentoring relationships between female economics faculty and female graduate students (CSWEP, Spring 1994). Support for mentoring programs is bolstered by evidence of negative relationships between male faculty and female graduate students (see the review in Berg and Ferber, 1983), and evidence that graduate students tend to seek out same-sex role models (Gilbert, 1985). ${ }^{1}$

Concern over low representation of women is not unique to economics. For example, women are severely underrepresented in computer science, engineering, and physics departments, despite some recent improvements (Gries and Marsh, 1992). To remedy the underrepresentation of women in traditionally-male fields (including economics), a number of universities and advocacy groups propose formal mentoring programs. These programs may operate at different levels and in different ways, including--in addition to mentoring of graduate students by faculty--formal mentoring relationships between junior and senior faculty members (Douthitt 1993), and increased

\footnotetext{
'On the other hand, survey evidence presented in Shelburn and Lewellyn (1995) indicates possibly offsetting influences of the sex composition of the faculty. For example, they find that male students are more likely to socialize with (predominantly male) faculty, while women report more frequent invitations for discussions of their progress.
} 
hiring of women in traditionally male fields to encourage female students to pursue similar lines of study (Girgus, 1992; Canes and Rosen, 1995). Likewise, the National Science Foundation seems to have embraced the potential gains from mentoring. Earlier this year, the NSF established the 1996 Mentor Award, part of the 'Presidential Awards for Excellence in Science, Mathematics, and Engineering Mentoring Program.' The stated purpose of this program, and others like it, is to encourage the participation of underrepresented groups in these fields.

While there seems to be widespread acceptance of the view that mentoring will help solve the underrepresentation problem, this view has been subjected to relatively little empirical analysis. The goal of this paper is to provide new evidence, focusing specifically on the influence of role models and mentoring provided by female faculty on the success of female graduate students in economics. It is left to future research to examine whether our results generalize to other maledominated academic disciplines.

There are two paths one could take in evaluating the effects of mentoring. One is exemplified in research by Canes and Rosen (1995), who ask whether the presence of female faculty has an effect on female students; they looked at choice of college majors, whereas we examine success of female graduate students. This research strategy in some sense treats mentoring as a black box--something that may or may not occur when women are better represented among the faculty. A second strategy is to try to get inside the black box, and ask what specific forms of mentoring might be most productive. Of course, ultimately both types of evidence are important. In this paper, we describe evidence on the effect that female faculty in economics have on outcomes for female graduate students. We obtained most of our data by surveying all Ph.D.granting economics departments in the U.S., requesting information on all female Ph.D. graduates from 1973 to the present. This data set is unique in that it provides information on the individual's relevant characteristics (such as GRE scores) and their first job, as well as other measures not 
available in existing data sources. ${ }^{2}$

We focus primarily on the quality of the first job placement. The first job seems a critical step in the development of an academic career. Some studies find that males and females have similar placements at first jobs once account is taken of factors such as prestige of the graduate department. $^{3}$ On the other hand, a relatively recent study by Barbezat (1992) based on a survey of AEA members finds that, controlling for numerous characteristics of graduate programs, women as compared with men are relatively more likely to receive their first placement at liberal arts colleges as opposed to business schools or economics departments ranked in the top $30 .^{4}$ We use various measures of "rankings" of economics departments to measure graduate student success in job placements. We also measure graduate student success by the time to attain a first job, and rates at which students complete Ph.D. programs. Graduates with a longer time to attain their first job forego earnings early in their career; thus, those who attain a first job earlier have a higher lifetime value of earnings. The costs of beginning but not completing a Ph.D. program are probably considerably higher.

To test for role-model or mentoring effects, we use the sex of the student's dissertation chair and (alternatively) the number of female faculty and ratio of female faculty to female students. We

\footnotetext{
${ }^{2}$ The Universal Academic Questionnaire (UAQ) does not contain much of the information needed for this study. First, it contains no data on the qualifications of students entering Ph.D. programs. Second, it contains few details regarding their placements. Third, as explained below, it does not provide an accurate count of the number of female students beginning a program in each year.

${ }^{3}$ See Willis and Pieper (1992).

${ }^{4}$ This evidence ranges from marginally significant to significant at the five- or ten-percent level. Once controls are included for individuals' reported preferences, the sex differences in relative placement probabilities become insignificant, which may be the basis for Kahn's (1995) conclusion that gender differences in placements can be completely explained by predetermined characteristics (Kahn, 1995, p. 197). However, this survey was completed after individuals became employed. It thus seems entirely plausible that reported preferences adjusted to reflect actual outcomes, and hence themselves reflect the sex differences in placements.
} 
assume that the sex of the student's dissertation chair serves as a proxy for whether the student experiences a same-sex mentoring relationship; thus, this variable is introduced to address the mentoring relationship directly. If same-sex mentoring has a positive impact on graduates, we expect female students with a female chair to place earlier and in better jobs than other female students. ${ }^{5}$ In contrast, we interpret our evidence on whether increased representation of females on the faculty improves outcomes for female graduate students as more relevant to role-model effects, or possibly other aspects of mentoring relationships.

Three caveats should be mentioned at the outset, to avoid drawing overly strong conclusions from our research. First, our evidence is certainly not decisive with respect to all forms of mentoring. Although we attempt to go "inside" the mentoring black box with our evidence on the sex of the dissertation chair, rather than looking solely at the representation of women on the faculty, one can argue that we miss the essence of the mentoring relationship, and should instead have examined some other aspect of graduate students' experiences. ${ }^{6}$ However, regardless of how well we capture mentoring relationships with our data, in our view the results regarding the representation of women on the faculty are of independent interest. It is entirely possible that female role models, in and of themselves, have important consequences, so that the mere presence of women on the faculty does have beneficial effects on female graduate students (see, e.g., Ehrenberg, 1995). ${ }^{7}$ In fact, many colleagues report having heard (or made) this argument made with respect to hiring decisions.

${ }^{5}$ This assumes that a longer time to attain one's first job is not associated with better training and better placement. Our data indicate a strong negative association between years to complete graduate school and quality of placement, although this is not necessarily causal.

${ }^{6}$ See Adams (1992), Douthitt (1993), Elkiss (1995), and Newby and Heide (1992), for discussions of the mentoring relationship.

${ }^{7} \mathrm{~A}$ related possibility raised in the literature is that a certain number of women faculty is needed to attain a "critical mass" at which conditions might become more favorable to women (Etzkowitz, et al., 1994). 
Second, because the outcomes we study are related to success in the labor market, we cannot distinguish between effects of female faculty that operate through the quality of students' training, research, and other factors related to faculty input, and effects that operate through placement. In fact, additional female faculty could improve the training of female graduate students, but be offset by discrimination against students of female faculty members. ${ }^{8}$

Third, much of our evidence focuses on graduate student success defined in terms of placements at academic departments, and at higher-ranked departments within academia. These measures of success may be too narrow. Female colleagues have suggested to us that non-academic jobs and academic jobs in lower-ranked departments may sometimes be preferable for women, if factors such as chance of promotion, respect from colleagues, cooperation, etc., are superior at such jobs. In fact, one could argue that female graduate students with female mentors are made more aware of such factors, and may therefore sometimes prefer placements that are considered "worse" by the criteria we use. It is therefore important to keep in mind that our results are restricted to success as we define it. We offset this problem to some extent by studying years to completion and completion rates, since it seems to us that fewer years to completion and higher completion rates indicate greater success on any score.

Despite these caveats, the evidence is still informative. For example, if adding female faculty members has little positive effect on outcomes for female graduate students, then we at least know that this strategy in isolation is not likely to improve outcomes for these students.

\section{Existing Research on Role Models and Mentoring}

One set of studies related to role models and mentoring focuses on the influence of the sex

${ }^{8}$ Existing studies that examine placement of female graduate students provide no evidence on the sex of a student's dissertation chair or the sex composition of the faculty at a student's institution (Barbezat, 1992; McMillen and Singell, 1994; Singell and Stone, 1993). 
composition of college faculties on college major choices of female students. Dynan and Rouse (1995) study whether female students respond differently to introductory economics classes taught by women as opposed to men, asking whether the lower relative probability that a female chooses an economics major is raised by the presence of female role models in the classroom. They find that female faculty do not affect the probability that either males or females continued to study economics. Using longitudinal data from three schools, Canes and Rosen (1995) test whether an increase in the proportion of female faculty has a positive impact on the percentage of females studying science or engineering, finding no evidence to support this contention. Solnick (1995) studies this question (as well as questions regarding the effects of the sex composition of the student body) by comparing changes in academic majors among women at single-sex vs. coed colleges. ${ }^{9}$ She finds that women at single-sex colleges switch to traditionally male-dominated majors at a higher rate than women at coed colleges. However, she does not find that women at single-sex schools are any more likely to remain in traditionally male-dominated fields than are women at coed institutions.

Ehrenberg, et al. (1995) address the issue of female mentoring at the grade-school level. Using an 8th grade test score as a baseline, they test whether the sex or race of a student's 10th grade teacher affects the amount learned by the student, measured by the difference between the 8th grade score and the 10 th grade score. Although there was not a significant change in the amount of material learned, white female teachers tended to rate the performance of white female students higher than other students, even when controlling for the student's ability. One interpretation is that the white female teachers provide mentoring through encouraging evaluations. Thus, the white female student is perceived to benefit from the relationship, even though the student does not learn

${ }^{9}$ Tidball (1980) documents the higher percentage of female faculty at women's colleges. 
more material. As the authors note, it remains an open question whether the higher ratings ultimately confer some benefits.

A second set of papers extends the analysis to look at labor market as well as educational outcomes. Rothstein (1995) tests whether the proportion of female faculty affects future labor market and educational outcomes of female students. Using data from the NLS High School Class of 1972 surveys, she finds that the probability that females attain a higher degree is positively related to the proportion of females on the faculty. Although an advanced degree results in higher earnings, Rothstein does not find any evidence of a direct positive effect of a higher percentage of female faculty on earnings. In related work, although focusing on blacks who attend historically black colleges and universities (HBCU's), Constantine (1995) finds that respondents who attend HBCU's earn higher future wages than respondents attending other colleges. This contrasts with Ehrenberg and Rothstein's (1994) finding that although students at HBCU's are more likely than other black undergraduates to receive a bachelor's degree, there is not a significant wage differential between the blacks graduating from HBCU's and blacks graduating from other colleges. ${ }^{10}$

Johnson and Scandura (1994) address the issue of mentoring on the job, rather than in educational institutions. Using a sample of Certified Public Accountants, they test whether mentoring in general, or a specific type of mentoring (coaching, friendship, or role-model), influences the earnings of employees. Although the amount of mentoring was not significantly different between males and females, Johnson and Scandura show that the presence of coach-type mentors increases female wages. There is no corresponding effect for male employees, regardless of the type of mentoring relationship.

There are a smaller number of papers more closely related to the specific question and

\footnotetext{
${ }^{10}$ Constantine argues that these differences arise because she uses data further along in workers' careers.
} 
context we address in this study. Tolbert, et al. (1995) use female faculty turnover rates as a proxy for the level of mentoring experienced by females in an academic department (a low turnover rate is presumed to be associated with a higher or more successful level of mentoring). ${ }^{11}$ They find that, over some range, a higher proportion of women in academic departments resulted in higher turnover, which they interpret as consistent with the view that as the relative size of a minority grows, there is increased competition among its members. However, as the minority proportion reaches a critical mass (estimated at 35-40 percent), the level of competition among minority members decreases and turnover rates fall, suggesting that minority faculty members only serve as role models or mentors when the proportion of the minority is above a threshold level. Etzkowitz, et al. (1994) also present descriptive evidence from the science field that supports this view.

To summarize, the evidence on role models and mentoring presents somewhat of a mixed bag. Looking at college students, the evidence suggests some role-model effects on choice of college major and educational attainment, but no direct effect on labor market outcomes (at least for women). With respect to female faculty, there is certainly no compelling evidence of positive rolemodel or mentoring effects. Finally, we have not yet come across any research on the potential impact of role models and mentors on the success of female graduate students, in economics or in any other field.

\section{The Sample and Data}

Beginning in November 1994, we surveyed all Ph.D.-granting economics departments in the United States. The two-part survey, which consists of a section on faculty and a section on female Ph.D. students, collects all available data from 1973 to the survey date, although some departments provided information on students beginning in the mid-1960's (see Appendix for survey forms and a

${ }^{11}$ Of course, turnover could sometimes stem from offers of employment at better departments, which should perhaps be thought of as success. 
copy of the letter sent to department chairs). In the faculty section, we requested information on the number of tenured and non-tenured female faculty and the total number of faculty. In the graduate student section, we requested information on female Ph.D. students who had been placed in jobs. As explained below, we also had some interest in all female students who ever entered a graduate program. However, preliminary investigations indicated that departments would have much more difficulty providing data on all such students than on the subset of those who were placed. We solicited information on the year of program entry, citizenship status (U.S. or foreign), the math GRE score, ${ }^{12}$ the sex of the dissertation chair, and the employer and year of the graduate's initial job placement.

Of the 130 programs surveyed, 58 programs returned at least one section of the survey. This yielded at least partial information on 709 graduate students. We restrict the sample to those who began their graduate study after 1972 (since we only requested and received information on faculty beginning in 1973), and who attained a job by the survey date. We exclude those whose placement was outside the U.S., and those with no job placement data. When the initial job is at a multicampus university, we assume job placement at the main campus unless the department reports otherwise. We classify the handful of placements in university research jobs as non-academic. Finally, individuals attaining a postdoctoral position (in which case we have no information on subsequent jobs) are included only in the analyses of the time to attain a first job.

We use the data from our survey to construct five outcome variables measuring the success of graduate students: four that measure the graduate's relative job placement, and one that measures the time required to complete the doctoral program. We measure the time to completion from the

${ }^{12} \mathrm{~A}$ small number of schools reported the GRE percentile instead of the GRE score. We converted the GRE percentiles into GRE scores, using the yearly publication "Guide to the Use of the Graduate Record Examinations Programs." 
date a graduate began studying to the date of the initial job placement. The first measure of job placement is a dummy variable indicating whether the woman was placed in an academic job (in the United States). The second is whether the initial academic job is in a Ph.D.-granting program or not (now excluding non-academic positions). The two remaining measures of job placement are based on published rankings of departments in which students are placed. Depending on the level of detail supplied by respondents, and limitations of the published rankings, we are sometimes unable to classify all observations in terms of each of these outcome measures, in which case the observations are dropped from the corresponding analysis.

The published ranks are from two sources: the National Resource Council's (NRC) 1992 report, and the rankings used by the American Economic Association's (AEA) Commission on Graduate Education in Economics (Hansen, 1991), a five-tier quality ranking of most Ph.D.granting institutions. We define the variable based on the NRC report as the rank based on faculty quality. ${ }^{13}$ The rankings are inverted so that the top department gets the highest ranking (107). We augment the AEA classification by adding a sixth tier, which includes all Ph.D.-granting departments not included in the rankings, and a seventh which includes non-Ph.D.-granting departments (since we are studying placements, whereas the tiers were developed to study graduate programs); these tiers are inverted so the highest number refers to the top tier. We also use these rankings to measure the quality of the institutions from which the students received their Ph.D.'s.

Finally, based on some of the findings reported in the existing literature, we wanted to obtain a measure of the likelihood that women complete the Ph.D. program. As noted above, obtaining records on all women who enrolled in Ph.D. programs posed overly-extensive demands

\footnotetext{
${ }^{13}$ Both sets of rankings are from a single year, so we do not detect changes in quality of placements over time. However, rankings of departments are very stable. For example, the correlation between the 1982 and 1993 NRC rankings is .95 .
} 
on the survey respondents. To obtain a measure of completion, therefore, we use the UAQ, which includes information on students and faculty in economics departments. This survey, which is mailed in the fall of each year, does not contain an ideal measure of completion rates. However, it elicits the numbers of male and female $\mathrm{Ph} . \mathrm{D}$. students registered for the previous fall (unfortunately, not broken down by years enrolled in the program), and the number of Ph.D.'s awarded to males and females during the previous academic year. If we denote the number of female students $R_{t}$, and the number of Ph.D.'s awarded to females $\mathrm{D}_{\mathrm{t}}$, and assume 1) that students take five years to complete their Ph.D., and 2) that all students are registered, then a crude estimate of the completion rate for female students initially enrolling in year $t$, is $\left(D_{t+5} / R_{t}\right) \times 5$. Note that the denominator will be inaccurate to the extent that the number of female graduate students varies by year. The numerator will be accurate, however, as long as the assumption regarding years to completion is correct. Also note that nothing constrains this estimate of the completion rate to be below one; to avoid influential outliers we drop a handful of observations with estimated rates exceeding two. Finally, note that this measure is available for school-year observations, as opposed to the individual-level data collected in our survey. We can form corresponding school-year observations on the female faculty variables using our survey data, and match by school and year to the UAQ.

We also use the UAQ to assess the quality of some of the data requested in our survey that is also requested in the UAQ. In particular, both our survey and the UAQ include data on the number of tenured and non-tenured female faculty. In part because respondents to our survey appear not to have been fully consistent with respect to the inclusion of instructors and other non-tenure-track faculty, the correlations are considerably below one for non-tenured faculty. Nonetheless, they appear reasonably high: .88-.89 for tenured female faculty, and $.60-.78$ for non-tenured female faculty, depending upon whether (as discussed below) we look at the faculty numbers as of students' 
third year or the year prior to their enrollment. ${ }^{14}$

\section{The Empirical Approach}

We estimate econometric models for each of our outcome variables as functions of the individual's math GRE test score and citizenship (U.S. vs. non-U.S.), in order to control for differences in abilities and qualifications across individuals, as well as characteristics of the graduate program including tier and faculty size. As already explained, our proxies for role models and mentoring are the representation of women on the faculty (measured various ways), and whether the student had a female dissertation chair. Based on the assumption that most students begin their dissertation research in their third year, and that this is when mentoring begins to be most important, we measure the representation of women on the faculty as of the beginning of the third year for each student. ${ }^{15}$ We examine the effects of the total number of female faculty as well as the number of tenured female faculty, because the latter may provide stronger role models or mentoring relationships.

All of our observations are outcomes for female graduate students, which entails an important implicit identifying assumption in our approach. Specifically, we assume that changes in the sex composition of the faculty do not affect outcomes for male students. We would ideally like to have data on male and female students, and to estimate the differential effect on them of, for example, additions of females to the faculty. However, requesting data on male graduate students would have been asking too much of those who supplied the data, given the far greater number of

\footnotetext{
${ }^{14}$ These estimates are based on overlapping observations in the two data sources, approximately 100 observations depending on the exact variable used. Obviously, we can also use the female faculty variables constructed from the UAQ as independent variables when we study completion rates; we report such results below.

${ }^{15}$ The Committee on Graduate Education reports that coursework should take only two years to complete (Hansen, 1991). Our qualitative results were not sensitive to using data from the second year instead.
} 
male students. We assume, instead, that the other control variables (GRE scores, department size, and year and school dummy variables) adequately capture sources of variation in outcomes for male students. Of course, even if female faculty (or dissertation chairs) help male and female graduate students alike, the results would be of interest, although they would then suggest that female faculty are better mentors per se, not necessarily better same-sex mentors. ${ }^{16}$

A potentially important problem is that of endogenous selection. For example, suppose that the highest-quality female students enter programs with relatively high numbers of female faculty, either because of self-selection or more aggressive recruiting. Then given that we do not measure all dimensions of the quality of incoming students, we could find a positive relationship between females on the faculty and female student performance that reflects neither role-model nor mentoring effects. ${ }^{17}$ To mitigate this problem, in some specifications we include as control variables the same measures of the representation of females on the faculty for the year before the student began, since it is this measure that, if any, is likely to be associated with endogenous selection.

\section{Descriptive Statistics}

Figure 1 and Table 1 report descriptive statistics for our data. Figure 1 summarizes the distribution of observations across years and department tiers. To some extent, departments in lower tiers (which are lower quality) are more strongly represented in the later years of the data. Because of such changes in sample composition over time, our data cannot be used to generate consistent time series. Table 1 reports statistics for the full sample, for graduate departments broken into tiers, and for (roughly) the two decades covered by our data. The figures in the table are

\footnotetext{
${ }^{16}$ When we look at completion rates, we can actually assess different impacts on men and women, since we can use the UAQ data to estimate these rates for men and women.

${ }^{17}$ Alternatively, those women most in need of mentoring may select such departments, creating bias in the other direction.
} 
consistent with many of our expectations, which helps to confirm the validity of the data. For example, students from higher-tier departments are more likely to be placed in Ph.D.-granting departments ${ }^{18}$ and higher-ranked or higher-tier departments, to have higher GRE scores, are more likely to be U.S. citizens and to come from larger departments, and have higher completion rates.

Table 1 also provides descriptive statistics on female faculty. The average number of female faculty is slightly higher at higher-tier departments (although overall department size is also higher), while the average number of tenured female faculty is lower. The ratios of female faculty to students are highest at the middle-tier departments. The proportions of female students with female dissertation chairs are very low across the board.

Despite our caveats regarding comparisons over time, the estimates in columns (5) and (6) may provide some crude evidence on the relationship between female faculty and the success of female graduate students. All four of the female faculty measures (numbers and ratios) increased from the 1973-1980 period to the 1981-1990 period. At the same time, all of the variables measuring success of female graduate students increased. The improvement in these latter variables occurs despite the shift of the sample toward lower-quality departments in later years, suggesting that this improvement is not spurious. Consequently, these comparisons might suggest that adding female faculty contributed to the greater success of female graduate students. Of course, these numbers tell us nothing about whether the improvements for female graduate students occurred in those departments that added female faculty. To address these and many other issues, we next turn to regression analysis of the micro data.

${ }^{18}$ They are less likely, however, to be placed in academic jobs, presumably because federal employers (the FTC, BLS, Federal Reserve Board, etc.) tend to hire from better departments. This suggests that we should be cautious in interpreting an academic placement as "better." 


\section{Regression Analysis}

Table 2 presents our baseline regressions for the six outcomes described in the previous section. In these regressions we include the variables--other than those related to role models and mentoring--that may be associated with graduate student outcomes. We present these results in part to check whether the data conform to expectations with regard to questions unrelated to the hypotheses we are testing. We estimate the models with just these control variables, then adding year and school dummy variables to control for secular changes and for department-specific effects. In the following tables, we turn to the evidence on role models and mentoring.

Table 2 reveals that U.S. citizens receive lower placements, with the exception of the academic/non-academic distinction. They are significantly less likely to obtain a job in a Ph.D.granting department, and they obtain placements in lower-tier and lower-ranked departments (significantly so in the first case). Students from higher-tier departments, on the other hand, do better in terms of placement at Ph.D.-granting institutions, placement in higher-ranked departments, and completion rates. ${ }^{19}$ Looking at GRE scores, almost without exception students with higher scores obtain higher placements--again with the exception of academic vs. non-academic placements--and finish more quickly, although most of the estimated coefficients are not statistically significant. Finally, graduate department size is largely unrelated to most of the outcomes we study. On the whole, however, the data appear to behave as we would expect, as students with higher test scores and students from better institutions get better placements and finish more quickly and with higher probability. ${ }^{20}$

\footnotetext{
${ }^{19}$ This parallels results in Barbezat (1992), Broder (1993), and Moore, et al. (1983).

${ }^{20} \mathrm{Of}$ course better schools attract better students. This is presumably why the estimated effect of GRE scores sometimes falls considerably once school dummy variables are added. Also, students likely differ on unmeasured dimensions systematically correlated with departments, so the estimated effects of department tier should not necessarily be interpreted as causal.
} 
Table 3 turns to evidence on role-model and mentoring effects on placement at an academic institution. The entries next to the letters A-D explain variations in the specification. The column headings indicate the alternative proxies used for role models or mentoring. Looking first at columns (1) and (2), in the first three rows the estimated coefficients of the number of female faculty (total or tenured) are small and insignificant. In the fourth specification (Panel D) we add a control for the number of female faculty in the year prior to the student's enrollment. This is intended to control for selection of students based on characteristics of departments with respect to female faculty. In this specification, we identify the effect of the number of female faculty from the change in this variable from the year prior to the student's enrollment to the student's third year, "solving" the selection problem by identifying effects from variation in female faculty that occurred after the student decided to enroll; obviously, this asks a lot of the data, given that the female faculty variables from the third year and the year prior to enrollment are likely to be highly correlated. In Panel D, the estimated effects of total or tenured female faculty are again small and insignificant. Certainly there is no evidence of a positive effect of the number of female faculty on the probability that female graduate students are placed at academic departments.

In columns (3) and (4) we instead look at ratios of female faculty to female students. The results in Panels A-C now indicate positive but insignificant effects on outcomes for female graduate students. Once we control for selection in Panel D the estimated effects of the ratio of total or tenured female faculty to female graduate students become negative, although still remaining small and insignificant. Overall, these results are most consistent with no causal effect of increases in the ratio of female faculty to female students on outcomes for female graduate students, although we recognize that our ability to identify such effects in Panel D (and Panel C, to a lesser extent) may be limited.

Finally, column (5) looks at the mentoring relationship in terms of whether the dissertation 
chair was female. The estimated effects on the probability of placement at an academic department are negative for each of the specifications we can estimate, and are marginally significant. ${ }^{21}$

Overall, the message from Table 3 is that there is no compelling evidence of positive role-model or mentoring effects when the outcome considered is placement at academic institutions. ${ }^{22}$

Table 4 turns to the evidence regarding placement at a Ph.D.-granting department. Looking at column (1), the estimated coefficient of the number of female faculty in the third year is negative but insignificant in all four specifications. In column (2), the estimated coefficients are also insignificant, although positive in Panels C and D. Columns (3) and (4) look at ratios of female faculty to female graduate students, rather than levels. The results are very similar to those in columns (1) and (2), and in fact in column (3), once we control for selection in Panel D the estimated effect of the ratio of female faculty to female graduate students has a significant negative effect on the probability of placement at a Ph.D.-granting department. However, the sign is reversed (although the estimated coefficient is insignificant) when we restrict attention to tenured female faculty in column (4). Column (5) looks at the mentoring relationship in terms of whether the dissertation chair was female. The estimated effects on the probability of placement at a Ph.D.granting department are relatively small and statistically insignificant for each of the specifications we can estimate. Overall, the evidence in Table 4 provides no statistically significant evidence of

\footnotetext{
${ }^{21}$ For this mentoring variable, there is no corresponding variable for the year prior to enrollment to include in order to correct for endogenous selection. We could attempt to control for this selection by including numbers of total or tenured female faculty from the year prior to enrollment, since this is likely related to the probability of having a female dissertation chair. When we did this, the qualitative conclusions did not change; results are available from the authors upon request. Another consideration is that female dissertation chairs are likely to be younger, on average, than male chairs, given the more recent entry of women into the profession. To the extent that age of the dissertation chair affects placements positively, the results are biased against finding evidence of mentoring effects; we did not collect data on the age of the dissertation chair.

${ }^{22}$ If women are overrepresented in fields with better non-academic options, this could dilute any role-model or mentoring effects on academic placements.
} 
positive mentoring effects when the outcome considered is placement at $\mathrm{Ph} . \mathrm{D}$.-granting departments. Indeed, many of the signs of the estimated coefficients are in the opposite direction, although they are generally not significant.

In Table 5, we instead look at placement of female graduate students in terms of the tier of the hiring department, based on regression estimates using the numerical tier of the department as the dependent variable. ${ }^{23}$ In this case, there is somewhat stronger evidence of--if anything--negative role-model or mentoring effects, especially when we look at the total number of women faculty, or the ratio involving this number. In the columns corresponding to these variables (columns (1) and (3)), the estimated effects are negative, and significant at the five- or ten-percent level before we include school dummy variables. Table 6 looks at a similar outcome, although classifying the department of placement by NRC rank, rather than tier. In this table, most of the estimated coefficients are negative but not statistically significant. Again, though, for the variables involving the total female faculty there is some evidence of negative role-model effects; for the ratio of total female faculty to female students, once school dummy variables are added the t-statistics exceed 1.5 .

Thus, using four alternative definitions of outcomes with regard to placement, there is quite clearly no evidence suggesting that role-model or mentoring relationships--insofar as they are reflected in numbers or ratios of female faculty or female dissertation chairs--increase the success of female graduate students.

This negative conclusion is moderated somewhat, however, when we measure success in terms of number of years in graduate school and completion rates. Table 7 reports regression results using years to completion as the outcome measure. In columns (1)-(4) most of the estimated

\footnotetext{
${ }^{23}$ The results were similar using ordered probit models.
} 
coefficients are negative, indicating that female graduate students finish more quickly when there are more female faculty. The evidence is statistically significant or marginally so when we look at the number of female faculty (total or tenured). However, the estimates change once we attempt to control for selection, with the estimated effects becoming insignificant in columns (1) and (2), but positive and significant (at the ten-percent level) in column (3). The estimates in column (5) are positive, indicating that a female chair results, if anything, in a longer time to completion; however, these estimated coefficients are insignificant. Thus, this table provides some mixed evidence of positive female role-model or mentoring effects.

Finally, Table 8 reports results for completion rates. Panels A-D present results measuring the completion rate using the UAQ data, but taking the other data from our survey. The estimated effects of the total number of female faculty, in column (1), provide some evidence of positive rolemodel or mentoring effects, as this variable has a sizable and significant (or marginally so) positive effect on completion rates. The magnitude of the effect implied by the estimates seems large, as the estimates imply that an increase of one female faculty member increases the completion rate by .1 to 2. On the other hand, an increase of one female faculty member is a large percentage increase, and, as explained above, our estimate of the completion rate is rather crude. The evidence is weaker for the other variables measuring female faculty, and never statistically significant (nor consistently positive) once year dummy variables are added.

Panels E-H report results using only the UAQ data, for as many observations on the schools in our data set as possible. With the UAQ data, we can only measure the number of female faculty, not the ratios of faculty to students. ${ }^{24}$ Using these data, the estimates are still mostly positive, but

\footnotetext{
${ }^{24} \mathrm{We}$ chose not to construct a crude measure of this ratio based on the student count used to construct the completion rate. Classical measurement error in the dependent variable only creates imprecise estimates, whereas measurement error in independent variables (such as the ratio of female faculty to female students) creates bias.
} 
smaller and no longer significant in any specification. As an alternative, we used the UAQ data for the subset of observations used in Panels A-D. The results replicated closely those using our survey data, indicating that while the results are sensitive to the sample of observations used, they are robust to using the female faculty variables from either data source (other than persistent differences in measurement across departments that are captured in the school dummy variables). ${ }^{25}$

Finally, completion rates are the one outcome that we can study for male as well as female graduate students, to look for differential effects of female faculty on male and female students. For the most part, the estimated effects were considerably closer to zero for male graduate students, although generally positive, suggesting that the estimates in Table 8 overstate somewhat the differential effects of female faculty on the completion rates of female graduate students. ${ }^{26}$ Thus, we read the overall results for completion rates as providing at best some limited evidence of positive role-model or mentoring effects on female graduate students.

An important consideration with respect to all of the results we have examined is whether there is sufficient variation in the female faculty variables to permit plausibly-sized effects of these variables on the outcomes we consider to be identified as statistically significant. Our sense is that we could identify effects of reasonable magnitudes as statistically significant, especially in the specifications in Panels A and B of Tables 3-8, which exclude school dummy variables. The standard errors in these tables suggest, for example, that increased probabilities of placement at academic or Ph.D.-granting departments would be significant if their magnitudes were in the range

\footnotetext{
${ }^{25} \mathrm{We}$ also tried averaging the estimated completion rates based on the assumption of five or six years to completion (since in our data mean years to completion exceeds five years), to reduce measurement error. In addition, we tried including the outliers for the estimated completion rates. In these alternative estimations, for a couple of specifications there was stronger evidence of beneficial effects of female faculty on completion rates. Results are available from the authors upon request.

${ }^{26}$ Results are available from the authors upon request.
} 
$.04-.08$ (or larger), and that effects on NRC rankings would be significant if they were in the range of 6-9. Thus, we regard the results as failing to find significant role-model or mentoring effects not primarily because of imprecise estimates, but because whatever effects exist are rather small (and sometimes in the wrong direction).

\section{Conclusions}

One potential method to increase the success of women in traditionally-male academic fields--including economics--is to encourage role-model or mentoring relationships between female faculty and female graduate students. Increased hiring of female faculty may be one way to promote such relationships. Having female faculty serve as dissertation chairs for female graduate students may be another. The evidence in this paper addresses the question of whether either of these strategies results in better outcomes for female graduate students. The evidence is based on survey information on female graduate students and faculties of Ph.D.-producing economics departments, covering the mid-1970s to the early 1990 s.

With respect to first jobs, the empirical evidence provides no support for the hypothesis that outcomes for female graduate students are improved by adding female faculty members, or by having a female dissertation chair. This is true in relatively "demanding" specifications in which we identify the effects of female faculty or dissertation chairs from within-school variation (over time), and also in specifications that exploit cross-sectional as well as time-series variation. It is also true whether or not we attempt to control for selection of female graduate students into different departments based on the representation of women on the faculty prior to students' enrollment.

However, with respect to time to complete graduate school, and the completion rate, there is some limited evidence of beneficial effects of female faculty members. This evidence is not robust across all specifications, but we think there is sufficient evidence to believe that there is a reasonable possibility that this effect exists. 
We do not think that our relatively unsupportive evidence on role-model or mentoring effects should be interpreted as implying that role-model or mentoring relationships between female graduate students and female faculty hold no promise for improving outcomes for female graduate students. Our evidence does not rule out the possibility that an explicit mentoring program may have some benefits. In addition, our evidence does not permit us to rule out the possibility that adding female faculty or having a female dissertation chair improves the training of female graduate students, but that such students suffer from discrimination in the labor market against their female faculty "recommenders," so that any potential benefits on placement of female students are offset. Evidence on these latter two questions requires additional research.

Despite the remaining questions, we think the lack of evidence that adding female faculty or increasing the proportion of female graduate students with female dissertation chairs improve placements for female graduate students, and the modest evidence of beneficial effects on completion, is informative. With our data, we cannot tell whether this generally weak evidence arises because such changes do not spur constructive mentoring relationships, because mentoring relationships with female faculty are not relatively more productive, or because there are offsetting responses to the same changes that create constructive mentoring relationships. Nonetheless, the evidence indicates that relatively simple solutions to the lagging success of women in economics-such as an emphasis on hiring female faculty, and arranging for female-female mentoring relationships via the dissertation chair--may be largely ineffective, especially when it comes to placing female graduate students in more prestigious jobs. 


\section{$\underline{\text { References }}$}

Adams, Howard G. 1992. "Mentoring: An Essential Factor in the Doctoral Process for Minority Students." Mimeograph, National Consortium for Graduate Degrees for Minorities in Engineering and Science.

Attiyeh, Gregory, and Richard Attiyeh. 1994. "Testing for Bias in Graduate School Admissions." Mimeograph, University of Arizona.

Barbezat, Debra A. 1992. "The Market for New Ph.D. Economists." Journal of Economic Education, Vol. 23, No. 3, Summer, pp. 262-76.

Berg, Helen M., and Marianne A. Ferber. 1983. "Men and Women Graduate Students: Who Succeeds and Why?" Journal of Higher Education, Vol. 54, No. 6, November/December, pp. 62948.

Broder, Ivy E. 1993. "Professional Achievements and Gender Differences Among Academic Economists." Economic Inquiry, Vol. 31, No. 1, January, pp. 116-27.

Canes, Brandice J., and Harvey S. Rosen. 1995. "Following in Her Footsteps? Faculty Gender Composition and Women's Choices of College Majors." Industrial and Labor Relations Review, Vol. 48, No. 3, April, pp. 486-504.

Committee on the Economic Status of Women in the Economics Profession Newsletter. Spring, 1994, p. 19.

Constantine, Jill M. 1995. "The Effect of Attending Historically Black Colleges and Universities on Future Wages of Black Students." Industrial and Labor Relations Review, Vol. 48, No. 3, April, pp. 531-46.

Douthitt, Robin. 1993. "University of Wisconsin-Madison Women Faculty Mentoring Program Training Manual." Mimeograph, University of Wisconsin-Madison.

Dynan, Karen E., and Cecilia Elana Rouse. 1995. "The Underrepresentation of Women in Economics: A Study of Undergraduate Economics Students." NBER Working Paper No. 5299.

Ehrenberg, Ronald G. 1995. "Role Models in Education." Industrial and Labor Relations Review, Vol. 48, No. 3, April, pp. 482-5.

Ehrenberg, Ronald G., Daniel D. Goldhaber, and Dominic J. Brewer. 1995. "Do Teachers' Race, Gender, and Ethnicity Matter? Evidence from the National Educational Longitudinal Study of 1988." Industrial and Labor Relations Review, Vol. 48, No. 3, April, pp. 547-61.

Ehrenberg, Ronald G., and Donna S. Rothstein. 1994. "Do Historically Black Institutions of Higher Education Confer Unique Advantages on Black Students? An Initial Analysis." In Ronald G. Ehrenberg, ed., Choices and Consequences: Contemporary Policy Issues in Education (Ithaca, NY: ILR Press), pp. 89-139. 
Elkiss, Helen. 1995. "Mentors and Proteges: Women in Union Leadership." Mimeograph, University of Illinois at Urbana-Champaign.

Etzkowitz, Henry, Carol Kemelgor, Michael Neuschatz, Brian Uzzi, and Joseph Alonzo. 1994. "The Paradox of Critical Mass for Women in Science." Science, Vol. 266, October 7, pp. 51-4.

Gilbert, L. A. 1985. "Dimensions of Same-Gender Student-Faculty Role-Model Relationships." $\underline{\text { Sex }}$ Roles, Vol. 12, Nos. 1/2, pp. 111-23.

Girgus, Joan S., et al. 1992. "Program for Recruitment and Retention of Women Faculty in Science and Engineering: A Report to the Dean of Faculty Robert C. Gunning." Mimeograph, Princeton University.

Gries, David, and Dorothy Marsh. 1992. "The 1989-90 Taulbee Survey." Communications of the ACM, Vol. 35, No. 1, January, pp. 131-43.

Hansen, W. Lee. 1991. "The Education and Training of Economics Doctorates: Major Findings of the Executive Secretary of the American Economic Association's Commission on Graduate Education in Economics." Journal of Economic Literature, Vol. 29, September, pp. 1054-87.

Horn, Patricia. 1994. "Walls Are Falling for Women in Economics, But Slowly." CSWEP Newsletter, Winter, pp. 8-9, reprinted from The Christian Science Monitor.

Johnson, Nancy Brown, and Terri A. Scandura. 1994. "The Effect of Mentorship and Sex-Role Style on Male-Female Earnings." Industrial Relations, Vol. 33, No. 2, April, pp. 263-74.

Kahn, Shulamit. 1995. "Women in the Economics Profession." Journal of Economic Perspectives, Vol. 9, No. 4, Fall, pp. 193-205.

McMillen, Daniel P., and Larry D. Singell. 1994. "Gender Differences in First Jobs for Economists." Southern Economic Journal, Vol. 60, No. 3, January, pp. 701-714.

Moore, William, Robert Newman, John Raisian, and R. William Thomas. 1983. "A Quality Adjustment Model of the Academic Labor Market: The Case of Economists." Economic Inquiry, April, pp. 241-54.

Newby, Timothy J., and Ashlyn Heide. 1992. "The Value of Mentoring." Performance Improvement Quarterly, Vol. 5, No. 4, pp. 2-15.

Rothstein, Donna S. 1995. "Do Female Faculty Influence Female Students' Educational and Labor Market Attainments?" Industrial and Labor Relations Review, Vol. 48, No. 3, pp. 515-30.

Shelburn, Marsha R., and Patsy G. Lewellyn. 1995. "Gender Bias in Doctoral Programs in Economics." The Journal of Economic Education, Vol. 26, No. 4, Fall, pp. 373-82.

Singell, Larry D., and Joe A. Stone. 1993. "Gender Differences in Ph.D. Economists' Careers." Contemporary Policy Issues, Vol. 11, No. 4, October, pp. 95-106.

Solnick, Sara J. 1995. "Changes in Women's Majors from Entrance to Graduation at Women's and 
Coeducational Colleges." Industrial and Labor Relations Review, Vol. 48, No. 3, April, pp. 505-14.

Tidball, M. Elizabeth. 1980. "Women's College and Women Achievers Revisited." Signs, Vol. 5, No. 3, Spring, pp. 504-17.

Tolbert, Pamela S., Tal Simons, Alice Andrews, and Jaehoon Rhee. 1995. "The Effects of Gender Composition in Academic Departments on Faculty Turnover." Industrial and Labor Relations Review, Vol. 48, No. 3, pp. 562-79.

Willis, Rachel A., and Paul J. Pieper. 1992. "Academic Placements of New Doctorates in Economics." Mimeograph, University of North Carolina. 


\section{Appendix: Survey Documents}

November 2, 1994

Dear Professor

As you probably know, there is growing interest in the role of mentoring in the performance of female Ph.D. students. To study this question, I am collecting data on the presence of women in the faculty and performance of female graduate students, measured in terms of both job placement and time to complete the program. I am attempting to collect data from all Ph.D. granting departments in the U.S., and sincerely hope that you can help me.

Enclosed are two forms that a department administrator should be able to complete quickly. One form asks about the number and tenure rank of female professors. We would like to get information back to 1973 , but even if it is not possible to go back that far, any number of years of data would be helpful. The second form asks for limited information on female doctoral students. Again we would ideally like to get information back to 1973 , if possible. There is no need to include students beginning your program in 1991 or afterwards.

The identity of individual departments will be strictly confidential. The research that circulates will simply state that all Ph.D.-granting programs were surveyed, and a certain number responded. No data will be reported at the level of the individual department. Only means, regression results, etc., will be reported. The raw data will not be circulated.

Again I hope that you can find someone to provide these data. Naturally, I will be happy to share the results of the study with you. Please have your department administrator contact me if there are any questions. Also, please supply the name of a person whom we can contact with questions, if necessary.

Sincerely,

David Neumark

Professor of Economics 


\begin{tabular}{|c|c|c|c|}
\hline \multicolumn{4}{|c|}{$\begin{array}{c}\text { FACULTY SUCCESSION } \\
\text { DEPARTMENT OF ECONOMICS }\end{array}$} \\
\hline YEAR & $\begin{array}{c}\text { \# FEMALE } \\
\text { FACULTY } \\
\text { WITH TENURE }\end{array}$ & $\begin{array}{l}\text { \# FEMALE } \\
\text { FACULTY } \\
\text { WITHOUT } \\
\text { TENURE }\end{array}$ & $\begin{array}{c}\text { TOTAL \# } \\
\text { OF FACULTY } \\
\text { ( MALE \& } \\
\text { FEMALE) }\end{array}$ \\
\hline 1973 & & & \\
\hline 1974 & & & \\
\hline 1975 & & & \\
\hline 1976 & & & \\
\hline 1977 & & & \\
\hline 1978 & & & \\
\hline 1979 & & & \\
\hline 1980 & & & \\
\hline 1981 & & & \\
\hline 1982 & & & \\
\hline 1983 & & & \\
\hline 1984 & & & \\
\hline 1985 & & & \\
\hline 1986 & & & \\
\hline 1987 & & & \\
\hline 1988 & & & \\
\hline 1989 & & & \\
\hline 1990 & & & \\
\hline 1991 & & & \\
\hline 1992 & & & \\
\hline 1993 & & & \\
\hline 1994 & & & \\
\hline 1995 & & & \\
\hline
\end{tabular}




\begin{tabular}{|c|c|c|c|c|c|}
\hline \multicolumn{6}{|c|}{$\begin{array}{l}\text { FEMALE GRADUATE STUDENT SUCCESSION } \\
\text { DEPARTMENT OF ECONOMICS } \\
\text { AT: }\end{array}$} \\
\hline $\begin{array}{c}\text { YEAR } \\
\text { BEGAN } \\
\text { PRO- } \\
\text { GRAM }\end{array}$ & $\begin{array}{l}\text { U.S. } \\
\text { CITIZEN } \\
\text { YES/NO }\end{array}$ & $\begin{array}{l}\text { MATH } \\
\text { GRE } \\
\text { SCORE }\end{array}$ & $\begin{array}{l}\text { FEMALE } \\
\text { CHAIR OF } \\
\text { THESIS } \\
\text { COMMITTEE } \\
\text { YES/NO }\end{array}$ & $\begin{array}{l}\text { YEAR } \\
\text { OF } \\
\text { INITIAL } \\
\text { JOB } \\
\text { PLACE- } \\
\text { MENT }\end{array}$ & $\begin{array}{c}\text { INITIAL } \\
\text { JOB } \text { PLACEMENT }\end{array}$ \\
\hline & & & & & \\
\hline & & & & & \\
\hline & & & & & \\
\hline & & & & & \\
\hline & & & & & \\
\hline & & & & & \\
\hline & & & & & \\
\hline & & & & & \\
\hline & & & & & \\
\hline & & & & & \\
\hline & & & & & \\
\hline & & & & & \\
\hline & & & & & \\
\hline
\end{tabular}




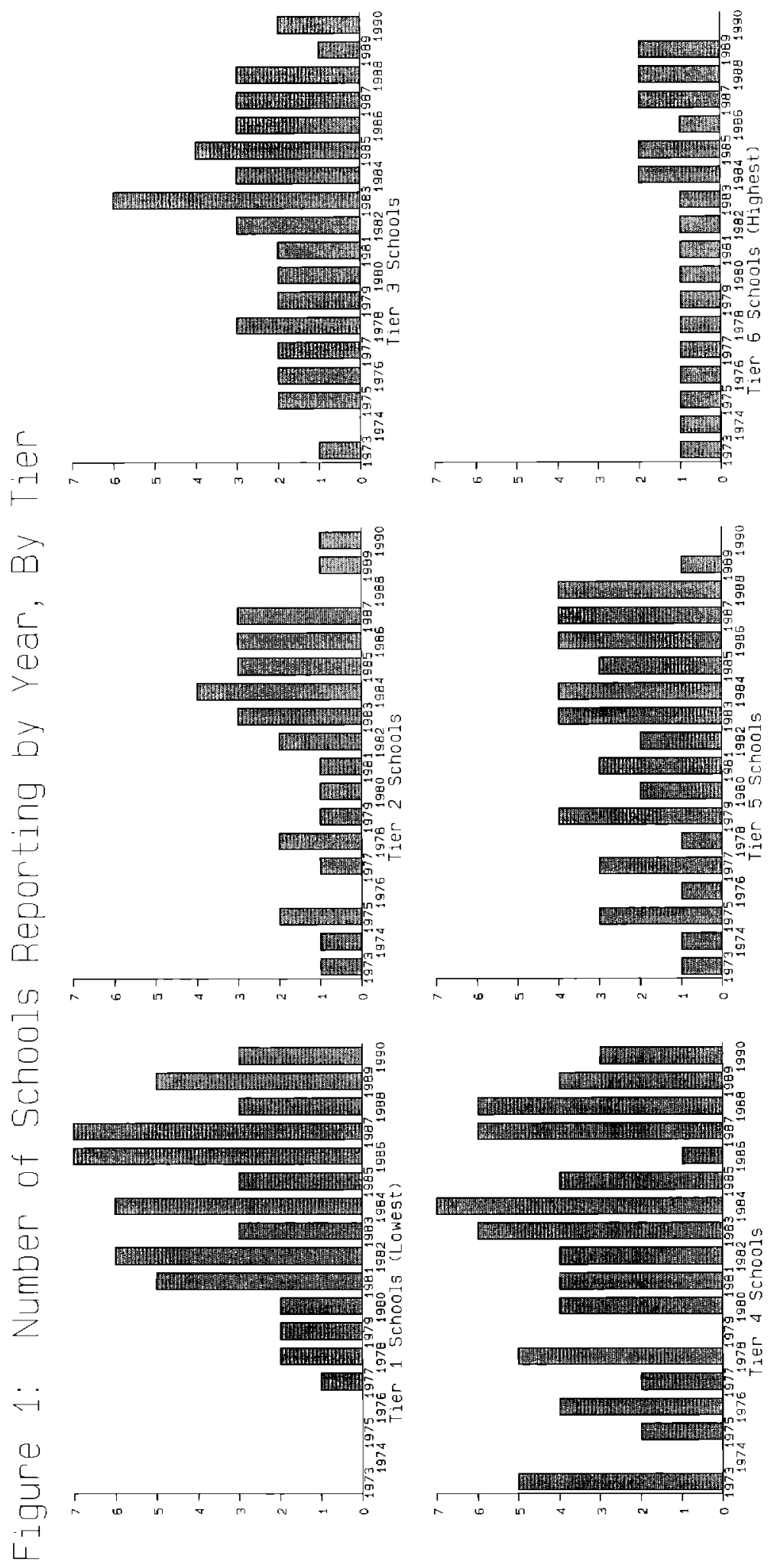




\begin{tabular}{|c|c|c|c|c|c|c|c|}
\hline & & 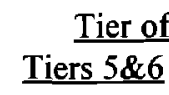 & Graduate De & artment: & Student's Beg & inning Year: & \\
\hline & $\frac{\text { Full Sample }}{(1)}$ & $\frac{\text { (Highest) }}{(2)}$ & $\frac{\text { Tiers } 3 \& 4}{(3)}$ & $\frac{\text { Tiers } 1 \& 2}{(4)}$ & $\frac{1973-1980}{(5)}$ & $\frac{1981-1990}{(6)}$ & $\frac{\text { Total \# Obs. }}{(7)}$ \\
\hline Academic placement & .67 & .64 & .68 & .71 & .61 & .70 & 459 \\
\hline $\begin{array}{l}\text { Placement at Ph.D.- } \\
\text { granting department }\end{array}$ & .53 & .65 & .54 & .34 & .47 & .56 & 290 \\
\hline $\begin{array}{l}\text { Tier of hiring } \\
\text { department (1-7) }\end{array}$ & $\begin{array}{c}2.66 \\
(1.95)\end{array}$ & $\begin{array}{c}3.29 \\
(2.18)\end{array}$ & $\begin{array}{c}2.58 \\
(1.83)\end{array}$ & $\begin{array}{c}1.76 \\
(1.25)\end{array}$ & $\begin{array}{c}2.29 \\
(1.81)\end{array}$ & $\begin{array}{c}2.80 \\
(1.99)\end{array}$ & 286 \\
\hline $\begin{array}{l}\text { Rank of hiring } \\
\text { department }\end{array}$ & $\begin{array}{c}67.1 \\
(30.1)\end{array}$ & $\begin{array}{c}74.9 \\
(28.1)\end{array}$ & $\begin{array}{c}66.6 \\
(29.3)\end{array}$ & $\begin{array}{c}44.3 \\
(27.0)\end{array}$ & $\begin{array}{c}63.3 \\
(31.4)\end{array}$ & $\begin{array}{c}68.3 \\
(29.7)\end{array}$ & 134 \\
\hline $\begin{array}{l}\text { Number of years } \\
\text { in graduate school }\end{array}$ & $\begin{array}{c}5.69 \\
(1.71)\end{array}$ & $\begin{array}{c}5.61 \\
(1.60)\end{array}$ & $\begin{array}{c}5.70 \\
(1.91)\end{array}$ & $\begin{array}{c}5.78 \\
(1.62)\end{array}$ & $\begin{array}{c}6.19 \\
(2.14)\end{array}$ & $\begin{array}{c}5.47 \\
(1.44)\end{array}$ & 459 \\
\hline Completion rate & $\begin{array}{l}.57 \\
(.57)\end{array}$ & $\begin{array}{l}.60 \\
(.54)\end{array}$ & $\begin{array}{l}.59 \\
(.63)\end{array}$ & $\begin{array}{c}.53 \\
(.45)\end{array}$ & $\begin{array}{l}.40 \\
. .46)\end{array}$ & $\begin{array}{c}.65 \\
(.60)\end{array}$ & 86 \\
\hline $\begin{array}{l}\text { Number of female } \\
\text { faculty }\end{array}$ & $\begin{array}{c}2.35 \\
(1.31)\end{array}$ & $\begin{array}{c}2.50 \\
(1.22)\end{array}$ & $\begin{array}{c}2.49 \\
(1.57)\end{array}$ & $\begin{array}{c}2.01 \\
(1.03)\end{array}$ & $\begin{array}{c}2.07 \\
(1.40)\end{array}$ & $\begin{array}{c}2.44 \\
(1.27)\end{array}$ & 362 \\
\hline $\begin{array}{l}\text { Number of tenured } \\
\text { female faculty }\end{array}$ & $\begin{array}{l}.84 \\
(.96)\end{array}$ & $\begin{array}{l}.71 \\
(.92)\end{array}$ & $\begin{array}{c}.99 \\
(1.19)\end{array}$ & $\begin{array}{c}.84 \\
(.70)\end{array}$ & $\begin{array}{l}.52 \\
(.87)\end{array}$ & $\begin{array}{l}.95 \\
(.97)\end{array}$ & 362 \\
\hline $\begin{array}{l}\text { Female faculty/ } \\
\text { female students }\end{array}$ & $\begin{array}{c}1.23 \\
(1.16)\end{array}$ & $\begin{array}{c}.82 \\
(.79)\end{array}$ & $\begin{array}{c}1.67 \\
(1.49)\end{array}$ & $\begin{array}{l}1.27 \\
(.98)\end{array}$ & $\begin{array}{c}1.10 \\
(1.11)\end{array}$ & $\begin{array}{c}1.28 \\
(1.18)\end{array}$ & 362 \\
\hline $\begin{array}{l}\text { Tenured female } \\
\text { faculty/female students }\end{array}$ & $\begin{array}{c}.47 \\
(.71)\end{array}$ & $\begin{array}{l}.21 \\
(.33)\end{array}$ & $\begin{array}{c}.74 \\
(1.01)\end{array}$ & $\begin{array}{l}.52 \\
(.55)\end{array}$ & $\begin{array}{l}.40 \\
(.79)\end{array}$ & $\begin{array}{l}.50 \\
(.69)\end{array}$ & 362 \\
\hline $\begin{array}{l}\text { Female dissertation } \\
\text { chair }\end{array}$ & .06 & .06 & .05 & .07 & .06 & .06 & 458 \\
\hline U.S. Citizen & .69 & .73 & .69 & .62 & .81 & .64 & 459 \\
\hline $\begin{array}{l}\text { Math GRE } \\
\text { Score }\end{array}$ & $\begin{array}{l}664.1 \\
(82.8)\end{array}$ & $\begin{array}{l}692.3 \\
(66.2)\end{array}$ & $\begin{array}{l}659.3 \\
(83.0)\end{array}$ & $\begin{array}{l}622.4 \\
(90.1)\end{array}$ & $\begin{array}{l}644.9 \\
(83.4)\end{array}$ & $\begin{array}{l}670.9 \\
(81.7)\end{array}$ & 306 \\
\hline $\begin{array}{l}\text { Graduate } \\
\text { Dept. Size }\end{array}$ & $\begin{array}{c}28.9 \\
(10.0)\end{array}$ & $\begin{array}{c}35.7 \\
(11.2)\end{array}$ & $\begin{array}{c}28.2 \\
(8.3)\end{array}$ & $\begin{array}{l}23.9 \\
(7.0)\end{array}$ & $\begin{array}{l}26.8 \\
(9.4)\end{array}$ & $\begin{array}{c}29.6 \\
(10.1)\end{array}$ & 253 \\
\hline
\end{tabular}

Department tier is based on the rankings in Hansen (1991); a graduate department rank of six indicates a school with a Ph.D. program of the highest quality, while a rank of one indicates a school with a Ph.D. program of the lowest quality. Hiring tier ranges from one to seven, with a lowest rank (equal to one) added for schools without Ph.D. programs, and the other ranks incremented by one. Department rank is based on the 1993 NRC rankings of the scholarly quality of program faculty. The rankings are inverted so that the top department gets the highest ranking. Estimates in this table are based on the maximum number of observations for which the variable is available for the regressions reported in the tables that follow. The completion rate is based on UAQ data for the subsample of observations also appearing in our data set. The variables involving numbers of female faculty are based on students' third years. Standard deviations are reported in parentheses for most variables, except for binomial variables. 
) :

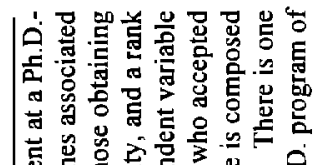

혈:

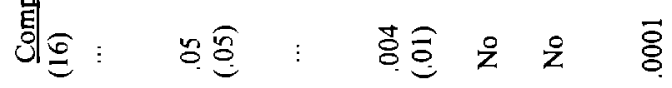

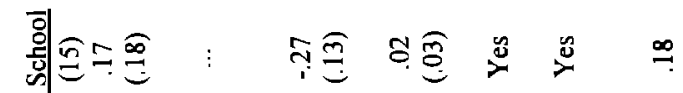

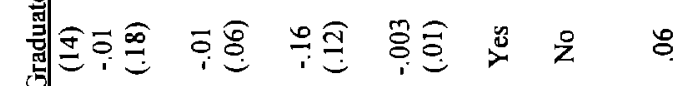

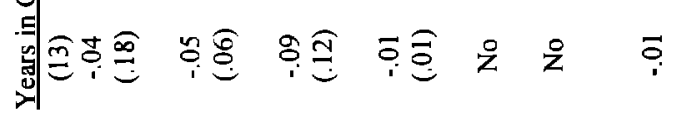

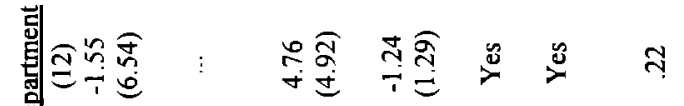

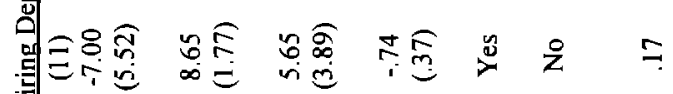

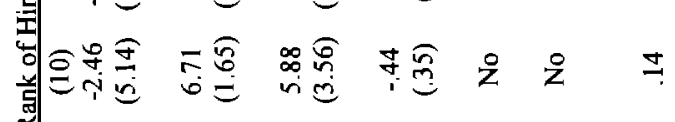

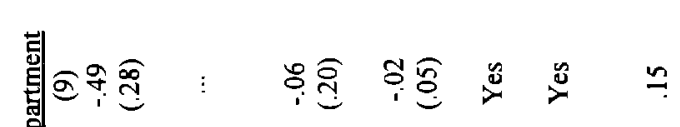

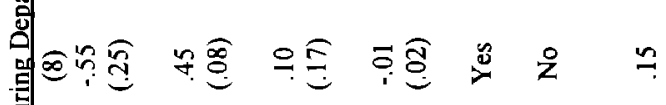

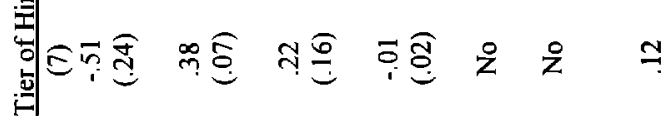

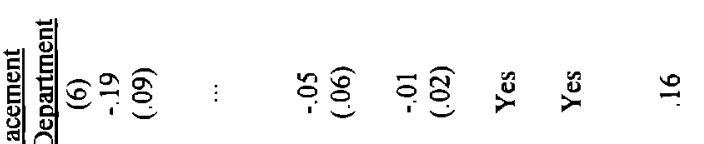

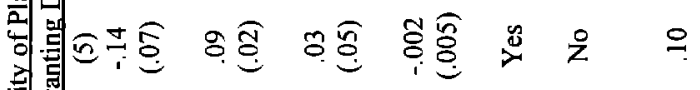

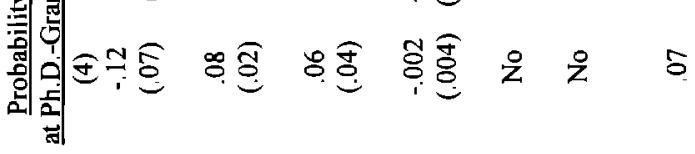

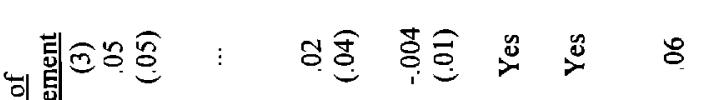

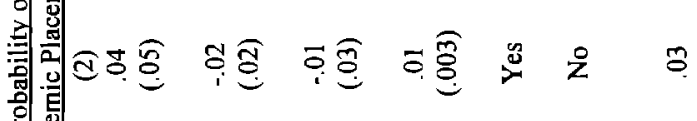

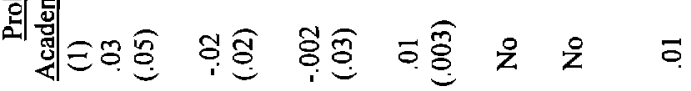

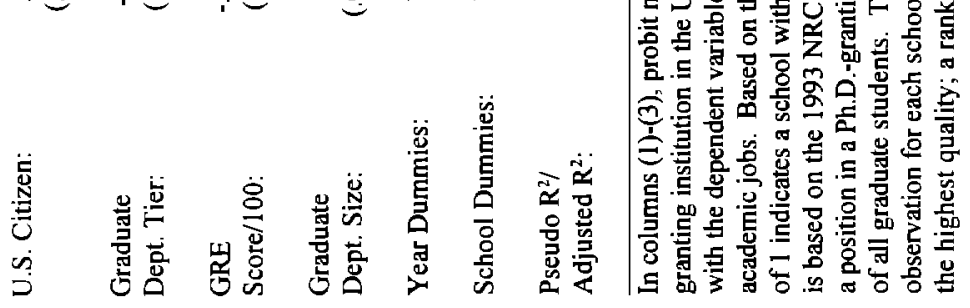




\section{Number of \\ Tenured \\ Number of \\ Female Faculty \\ Female Faculty}
A. Controls for U.S. Citizen, Dept. Tier, GRE Score, and Dept. Size:

B. Year dummy variables added:

C. School dummy

variables added:

D. Same as C, but with role-model/ mentoring variables from year prior to student's first year added:

Variables prior to first year:
(1)

(2)

$$
.004
$$

$-.004$

(.02)

$-.003$

(.03)

$-.01$

(.03)

.04

(.03)
.02

(.03)

.01

(.03)

.03

(.05)

.02

(.06)

.06

(.07)

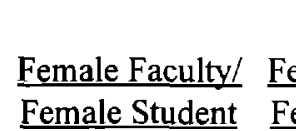

(3)

.03

(.02)

.02

(.02)

.01

(.03)

$-.02$

(.04)

.06

(.05)
Tenured

emale Facultyl Female

Female Student Dissertation Chair

(4)

(5)

.05

(.04)

$-.14$

(.09)

$-.14$

(.09)

(.04)

.01

(.06)

$-.15$

(.09)

$-.003$

(.08)

.05

(.10)

See notes to Tables 1 and 2 for descriptions of dependent variable, control variables, sample, and estimates. Female faculty are measured as of the student's third year, except in Panel D, where measures of number of female faculty and female faculty/female student ratio from the year prior to the student's first year are also included as controls. Each estimate reported is from a separate estimation. There are 362 observations with data on the number of female faculty and the female faculty/female student ratio (with somewhat fewer available in Panel D), and 458 with data on sex of dissertation chair.

Table 4: Probability of Placement at a Ph.D.-Granting Department

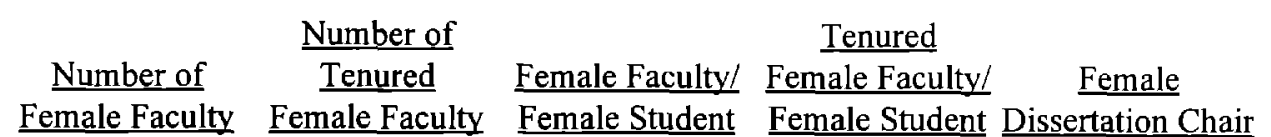

(1)

(2)

(3)

(4)

(5)

$-.04$

(.03)

$-.01$

(.04)

$-.04$

(.03)

$-.01$

(.05)

$-.03$

and Dept. Size:

$-.04$

(.03)

$-.02$

(.04)

$-.04$

(.03)

$-.0002$

(.05)

$-.08$

$-.01$

(.04)

.08

$-.03$

(.05)

.07

(.08)

(.16)

variables added:

(.08)

.08

(.10)

$-.16$

(.07)

.15

(.14)

$-.03$

(.11)

.15

(.08)

.04
$(.04)$

(11)

$\begin{array}{cc}-.04 & .08 \\ (.05) & (.10) \\ & \\ .04 & -.03 \\ (.04) & (.11)\end{array}$

$$
\text { (.08) }
$$

See notes to Tables 1 and 2 for descriptions of dependent variable, control variables, sample, and estimates. Female faculty are measured as of the student's third year, except in Panel D, where measures of number of female faculty and female faculty/female student ratio from the year prior to the student's first year are also included as controls. Each estimate reported is from a separate estimation. There are 235 observations with data on the number of female faculty and the female faculty/female student ratio (with somewhat fewer available in Panel D), and 289 with data on sex of dissertation chair. 
Table 6: Rank of Hiring Department

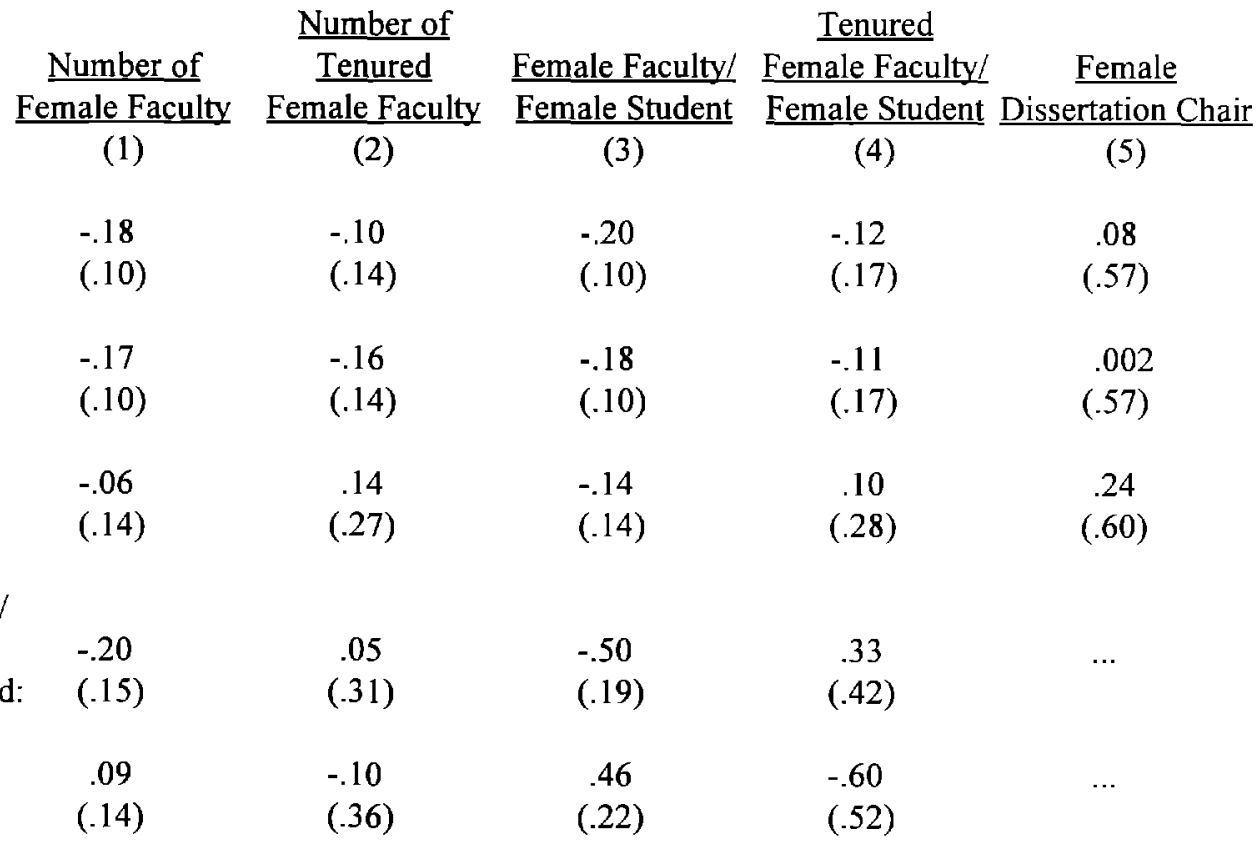
See notes to Tables 1 and 2 for descriptions of dependent variable, control variables, sample, and estimates. Female faculty are measured as of the student's third year, except in Panel D, where measures of number of female faculty and female faculty/female student ratio from the year prior to the student's first year are also included as controls. Each estimate reported is from a separate estimation. There are 230 observations with data on the number of female faculty and the female faculty/female student ratio (with somewhat fewer available in Panel D), and 285 with data on sex of dissertation chair.
A. Controls for U.S. Citizen, Dept. Tier, GRE Score, and Dept. Size:
B. Year dummy variables added:
C. School dummy
variables added:
mentoring variables from year
prior to student's first year added:
Variables prior to first year:
.09
(.36)
(.22)
(4)
(5)
.08
.002
$(.57)$
.24
$(.60)$
D. Same as C, but with role-model/
Variables prior to first year:

Table 6: Rank of Hiring Department

\begin{tabular}{|c|c|c|c|c|c|c|}
\hline \multirow[b]{2}{*}{ A. } & & $\frac{\begin{array}{l}\text { Number of } \\
\text { Female Faculty }\end{array}}{(1)}$ & $\begin{array}{c}\frac{\text { Number of }}{\text { Tenured }} \\
\frac{\text { Female Faculty }}{(2)}\end{array}$ & $\frac{\frac{\text { Female Faculty/ }}{\text { Female Student }}}{(3)}$ & $\frac{\begin{array}{c}\text { Tenured } \\
\text { Female Faculty/ }\end{array}}{\frac{\text { Female Student }}{(4)}}$ & $\frac{\frac{\text { Female }}{\text { Dissertation Chair }}}{(5)}$ \\
\hline & $\begin{array}{l}\text { Controls for U.S. Citizen, } \\
\text { Dept. Tier, GRE Score, } \\
\text { and Dept. Size: }\end{array}$ & $\begin{array}{l}-1.83 \\
(2.58)\end{array}$ & $\begin{array}{c}2.79 \\
(3.67)\end{array}$ & $\begin{array}{l}-3.50 \\
(3.16)\end{array}$ & $\begin{array}{c}.51 \\
(4.82)\end{array}$ & $\begin{array}{c}-1.25 \\
(14.34)\end{array}$ \\
\hline B. & $\begin{array}{l}\text { Year dummy } \\
\text { variables added: }\end{array}$ & $\begin{array}{l}-2.85 \\
(2.77)\end{array}$ & $\begin{array}{c}1.82 \\
(3.91)\end{array}$ & $\begin{array}{l}-4.97 \\
(3.53)\end{array}$ & $\begin{array}{c}-.12 \\
(5.18)\end{array}$ & $\begin{array}{c}.04 \\
(14.91)\end{array}$ \\
\hline C. & $\begin{array}{l}\text { School dummy } \\
\text { variables added: }\end{array}$ & $\begin{array}{l}-2.52 \\
(3.78)\end{array}$ & $\begin{array}{c}-.87 \\
(9.01)\end{array}$ & $\begin{array}{l}-8.97 \\
(5.66)\end{array}$ & $\begin{array}{l}-10.05 \\
(11.72)\end{array}$ & $\begin{array}{c}-8.73 \\
(15.68)\end{array}$ \\
\hline D & $\begin{array}{l}\text { Same as } C \text {, but with role-model/ } \\
\text { mentoring variables from year } \\
\text { prior to student's first year added: }\end{array}$ & $\begin{array}{l}-2.76 \\
(3.99)\end{array}$ & $\begin{array}{c}-6.70 \\
(10.46)\end{array}$ & $\begin{array}{c}-11.53 \\
(7.42)\end{array}$ & $\begin{array}{c}-7.34 \\
(17.42)\end{array}$ & $\ldots$ \\
\hline & Variables prior to first year: & $\begin{array}{c}-.75 \\
(3.55)\end{array}$ & $\begin{array}{l}11.64 \\
(9.34)\end{array}$ & $\begin{array}{c}2.84 \\
(6.28)\end{array}$ & $\begin{array}{c}-4.85 \\
(18.57)\end{array}$ & $\ldots$ \\
\hline
\end{tabular}

See notes to Tables 1 and 2 for descriptions of dependent variable, control variables, sample, and estimates. Female faculty are measured as of the student's third year, except in Panel D, where measures of number of female faculty and female faculty/female student ratio from the year prior to the student's first year are also included as controls. Each estimate reported is from a separate estimation. There are 106 observations with data on the number of female faculty and the female faculty/female student ratio (with somewhat fewer available in Panel D), and 133 with data on sex of dissertation chair. 


$\begin{array}{cc}\text { Number of } & \begin{array}{c}\text { Number of } \\ \text { Femured }\end{array} \\ \text { Female Faculty } & \text { Female Faculty }\end{array}$

(1)

(2)

$-.20$

(.08)

$-.17$

(.08)

$-.22$

(.09)

variables added:

D. Same as C, but with role-model/ mentoring variables from year prior to student's first year added:

Variables prior to first year:
$-.07$

(.11)

$-.08$

(.11)

$-.52$

(.18)

$-.31$

(.19)

$-.37$

(.22)
Tenured

Female Faculty/ Female Faculty/ Female

Female Student Female Student Dissertation Chair

(3)

(4)

(5)

$\begin{array}{llc}-.14 & -.15 & .40 \\ (.08) & (.13) & (.34)\end{array}$

$-.15$

$-.16$

(.13)

.43

(.08)

(.33)

$-.15$

$-.29$

(.20)

.30

(.10)

\section{.20 \\ (.12)}

$-.02$

(.26)

-.37
$(.15)$

$-.30$

(.33)

See notes to Tables 1 and 2 for descriptions of dependent variable, control variables, sample, and estimates. Female faculty are measured as of the student's third year, except in Panel D, where measures of number of female faculty and female faculty/female student ratio from the year prior to the student's first year are also included as controls. Each estimate reported is from a separate estimation. There are 362 observations with data on the number of female faculty and the female faculty/female student ratio (with somewhat fewer available in Panel D), and 458 with data on sex of dissertation chair. 
Table 8: Completion Rates

\section{Number of Tenured}

Female Faculty Female Facult

$(1)$
.20
$(.06)$

B. Year dummy variables added:

C. School dummy variables added:

D. Same as C, but with role-model/ mentoring variables from year prior to student's first year added:

Variables prior to first year:

E. Controls for Dept. Tier and Dept. Size, only UAQ data:

F. Year dummy variables added, only UAQ data:

G. School dummy variables added, only UAQ data:

H. Same as C, but with role-model/ mentoring variables from year prior to student's first year added, only UAQ data

Variables prior to first year:
(2)

.09

(.09)

$-.03$

(.17)

$-.02$

(.17)

$-.06$

$-.05$

.01

(.05)

.04

(.05)
$-.08$

(.11)

.08

(.11)

Tenured

Female Faculty $/$ Female Faculty $f$

Female Student Female Student

(3)

.05

(.06)

.02

(.07)

$-.01$

(.08)

.05

(.11)

$-.12$

(.11)

(4)

.04

(.08)

$-.004$

(.09)

$-.18$

(.15)

$-.14$

(.18)

-.12
$(.25)$

-.12
$(.25)$

...

...

.

See notes to Tables 1 and 2 for description of dependent variable, control variables, sample, and estimates. Data in Panels A-D are based on combined survey and UAQ data, with 71 observations. Data in Panels E-H use only the UAQ data for the same set of schools, with 155 observations in Panels E-G, and less in Panels D and H. Female faculty are measured as of the student's third year, except in Panels $D$ and $H$, where measures of number of female faculty and female faculty/female student ratio from the year prior to the student's first year are also included as controls. Each estimate reported is from a separate estimation. 